\title{
EDUCATIVE EFFECTS OF SPATIAL VISUALISATION
}

\begin{abstract}
The article deals with the issue of the impact of spatial visualization on education. It reports on some of the findings of a research project focused on defining the correlation between components of spatial intelligence and absorbing the information presented by planar or spatial visualization. The research examined educational impact of differences in mental models of lower-secondary school students watching spatial visualization in relation to mental models formed through watching planar visualization and also a level of cognitive strain of learners perceiving spatial and planar visualization in relation to their specific predispositions, namely to various components of spatial intelligence.
\end{abstract}

\section{Key Words}

Education, planar visualization, spatial visualization, mental model, spatial intelligence

\section{Miloš Prokýšek, Vladimír Rambousek}

Charles University in Prague, Faculty of Education prokysek@pedf.cuni.cz

\section{ARTICLE INFO}

Article type

Full research paper

doi: 10.7160/eriesj.2013.060103

Article history

Received: August 13, 2013

Received in revised form: March 4, 2013

Accepted: March 5, 2013

Available on-line: March 31, 2013

Prokýšek, M., Rambousek, V. (2013) "Educative Effects of Spatial Visualisation", Journal on Efficiency and Responsibility in Education and Science, Vol. 6, No. 1, pp. 24-23, ISSN 1803-1617, [on-line] www.eriesjournal.com/_papers/article_183.pdf 


\section{Introduction}

The premise of this paper on spatial visualization and its application in education is the presumption of the high educative potential of spatial visualization technology as a technical instructional tool and the expectation of spreading the technology into the school environment and into the educational sphere in general. However, spatial visualization as a scientific concept is not fully acknowledged. At the same time, spatial visualization has recently experienced accelerated development as well as diversification from the perspective of technological solutions and applications. In addition to classic technologies based predominantly on binocular parallax, there are emerging technologies based on holography, and even technologies based on direct spatial visualization or light field reproduction. Widely used technologies using monocular depth perception cues such as interposition, linear perspective or motion parallax cannot be seen as truly spatial.

These technologies are often marked as 3D. But the term 3D cannot be simply seen as a synonym for spatial visualization. This term (i.e. three-dimensional) simply means that the technology takes into account three dimensions, therefore making it 3D. The three dimensions do not necessarily convey the ability to express the location in space, therefore it does not necessarily mean spatial. E.g. when a computer game claims to be 3 dimensional, it is far from being spatial when viewed on a standard LCD display. Since the spatial depth is supported by monocular hints, these technologies are often marked as $2.5 \mathrm{D}$ and they represent the so called pseudo spatial visualization (Oh et al., 2011).
It can be assumed that truly spatial visualization would only be such a visualization that evokes binocular disparity, which together with motion parallax maximizes the perception of depth (Sekuler and Blake, 2005, p. 221).

In an attempt to more precisely classify the incorporation of spatial visualization means into the system, both technological and perceptual views should be taken into account. The perceptual characteristics should be considered as some of the most important aspects of the evaluation of spatial visualization means as it describes the substantial attributes of spatial visualization from the perspective of the viewer's perception no matter what the visualized model is. The perceptual characteristics are usually derived from the technological origin of the visualization and they are hence usually unchangeable for the given technology, or the possibility of change is quite limited.

From the technological perspective, spatial visualization means may be divided into four dominant bases: the technologies that are parallactic, direct spatial visualization technologies, light field systems and holographic technology.

From the perception perspective, spatial visualization means can be divided by using three perceptual axes. The first axis shows the number of subjects that can view the visualization. As for the number of viewers, there are two main possibilities of observation of spatial visualization, monoscopic (set for one viewer) or polyscopic (set for more viewers). If there are more viewers experiencing the spatial visualization at the same time, the perception is highly influenced by the ability of the visualization to mediate the active motive parallax.

The second axis shows the ability of the visualization to adjust to the change of physical location of the viewer in relation to the visualization by inducing the motion parallax. The motion 
parallax is, beside the binocular disparity, the second strongest cue in depth-perception (Schiller, Slocum, Jao and Weiner, 2011). This is very important for bringing the visualization closer to the real experience. We may also distinguish technologies supporting only passive parallax and active parallax (parallax emerging by changing the location of the viewer while the viewer perceives the change of the view point towards the model).

The third axis shows the form of visualization and reflects the subjective perception of visualization. The form can be convex, planar or concave. From the subjective perception of the scale of visualization, there are two extremes of this perceptual axis, total convex and total concave visualization. In total convex visualization, the viewer could observe the model in a "crystal ball" from any horizontal or vertical angle. In total concave visualization, the viewer could look in any vertical or horizontal direction, i.e. he would be "inside" the ball.

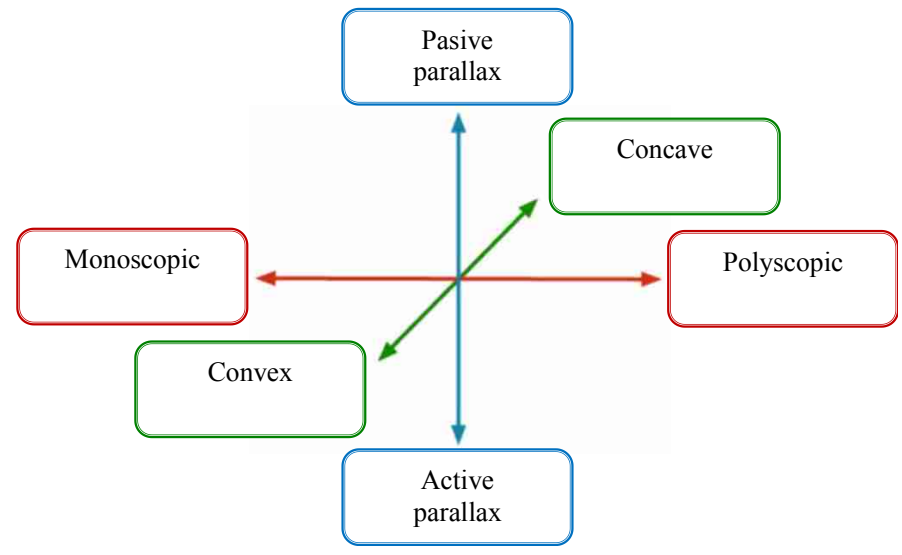

Figure 1: Axes of perceptual characteristics of spatial visualization
Classification of individual means of spatial visualisation can be based on the above mentioned perceptual characteristics, identifiable across the technologies regardless of the design and the principle of the device. It can be assumed that even technologies likely to emerge in the near future will have the same perceptual characteristics based on the perceptual aspects and will fall into the existing perceptual categories. Table 1 shows the technologies (or specific members of significant technological groups) as classified into perceptual categories.

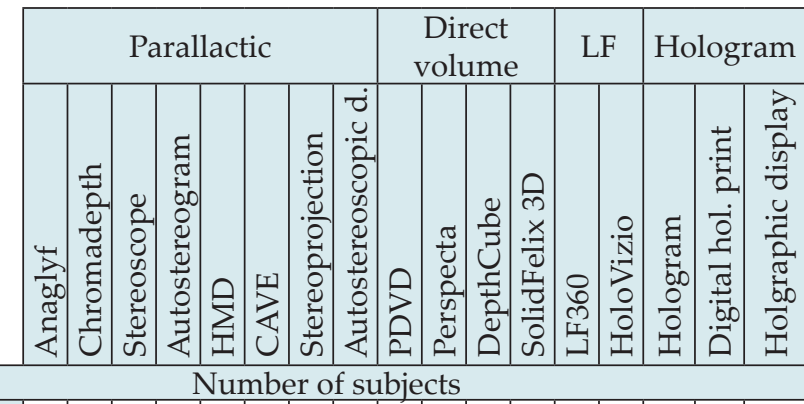

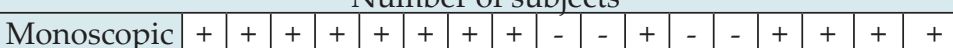

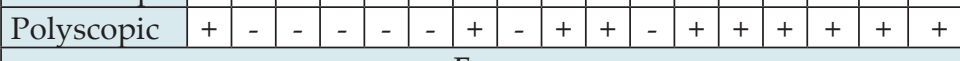
Form

\begin{tabular}{|l|c|c|c|c|c|c|c|c|c|c|c|c|c|c|c|c|c|}
\hline Convex & - & - & - & - & - & - & - & + & + & + & + & + & + & - & - & - & - \\
\hline Planar & + & + & + & + & - & - & + & - & - & - & - & - & - & + & + & + & + \\
\hline Concave & - & - & - & - & + & + & + & - & - & - & - & - & - & + & - & - & - \\
\hline \multicolumn{10}{|c|}{ Parallax } \\
\hline Passive & + & + & + & + & - & - & + & - & - & - & - & - & - & - & - & - & - \\
\hline Active & - & - & - & - & + & + & + & + & + & + & + & + & + & + & + & + & + \\
\hline
\end{tabular}

Table 1: Perceptual characteristics of spatial visualisation means

(LF $=$ Light Field, HMD = Head Mounted Display, CAVE $=$ Cave Automatic Virtual Environment, LF360 = Interactive 360 Light Field Display) (allows for $=$ ' + ', does not allow for $=$ ' - ') 
Depending on the kind of applied technologies and the pertinent application area, there is a wide range of various tools of spatial visualization for the visualization of both particular real world objects, as well as various virtual objects, complex virtual worlds or notion or data structures. Spatial visualization is also gradually finding its way into the area of education, so far primarily as an experiment, and presumably it may soon replace some teaching aids, or overcome them and thereby significantly contribute to a higher quality of education. It may be assumed that spatial visualization has certain perception and didactical specifics that influence the quality of the process of receiving educational contents, its processing and induced cognitive processes, and above all the processes of mental representation and creating mental models in relations to spatial intelligence of the perceiving subject (Sternberg, 2002).

The above mentioned premises have become the authors' focus as part of the research into spatial visualization, concentrating on characteristics, specifics, and the role and position of spatial visualization in education.

The field of spatial visualization is rather unclearly defined and its notion, from the perspective of education science, is characterized by certain conceptual and terminological inconsistency. The research on the usage of spatial visualization in education is usually focused on particular aspects which do not represent the topic in its whole complexity. Mainly, there are surveys on spatial imagination (Górska, 2005) and its development, or the correlation between spatial imagination and successfully learning certain subjects (Sorby, 2007). Some sources (Mikropoulos and Natsis, 2011) also show that the manner, by which mental representation of perceived reality is constructed, above all mental models, differ significantly in comparable groups of individuals, depending on whether planar or spatial models are used during the processes of creating such models representing the given object. Furthermore, there are surveys comparing the results of instruction, using either common or spatial visualization (Esparrachiari, 2005) and surveys on virtual reality or virtual learning environment (Dalgarno and Lee, 2010).

The survey on spatial visualization and its application in education that this article is based on, intends to contribute to solving this issue from technology, cognitive psychology, and methodology viewpoints.An important part of the research was an empirical inquiry bound to the above mentioned goal.

The concept of didactic specifics is an important aspect. It is generally defined by a combination of specific qualities and abilities, or specific technological, organisational, didacticlyfunctional and other, from a didactic point of view, relevant parameters of the material didactic means, distinguishing it from other means from a viewpoint of achieving educational goals.

In general, from a standpoint of visualisation specifics, we can emphasize especially the presentation of content, interpretation and control information relating to education, or subject matter in the most suitable manner taking into account the goal or conditions.

Didactic specifics of spatial visualization are primarily based on the fact that this way of presenting educational data features, unlike any other standard way of projected visualisation, another dimension and thus enables to provide directly information that would otherwise have to be modified. Spatial visualization in comparison to planar visualisation shows broader potential of visual communication based mainly on using binocular disparity and direct visualization of depth in the visualized content. This principal advantage may in a suitable situation contribute to a 
higher didactic efficiency. Spatial visualization, especially when immersive, can influence not only knowledge but also viewers' behaviour - a number of surveys prove that there are changes in mental models of behaviour as a consequence of playing video games. The influence of immersive environment in video games reinforces forming certain mental models more intensely than for instance watching television (Tamborski and Skalski, 2006).

Monoscopic systems of spatial visualisation primarily allow for a high level of individualisation and personalisation. They are suitable mainly for individualised educative forms with content and time differentiation in the lessons, although it is usually possible to use them in frontal teaching.

Polyscopic technologies of spatial visualisation enable more viewers to watch a visualised model at the same time and that determines them to be used in frontal teaching or group teaching.

The main didactic specific of the systems with active parallax is the possibility to explore a model through active motion of a viewer. A model visualised in this way is perceived by a viewer similarly to a real object and its effect on a viewer resembles real experience. Visual perception is less at odds with other position sensors.

From a didactic specifics point of view a determining factor of convex visualisation is the said fact that a viewer primarily perceives reality, does not lose continuity and spatial visualisation is only a part of his/her perceptual field. Didactic specific of concave visualization is the fact that viewers become a part of watched virtual world, which surrounds them.

Although it can be said that all means of spatial visualisation are to some extent interchangeable the adequacy of their application in didactic situations is determined, in addition to their didactic specifics, by visualised content (or visualised model) and parameters of the visualisation.

Attributes of visualisation of a model are defined, in addition to didactic purpose, by visual capabilities of chosen means of spatial visualisation, i.e. capabilities of the used technology limit the application of a specific model in teaching and possible parameters of its visualisation.

Complex character of a model relates to the graphical rendition of the template or complexity of a visualised model from the perspective of using simple graphical elements. Abstraction of a model represents the extent to which the visualisation is close to reality. Dynamism of a model enables to represent phenomena and actions in motion and progress, to capture causal links, changes in time and other time-dependent events. Colour can be used to differentiate certain parts of a model, highlight details, point out connections between various parts of a model, express characteristics of a model in certain part thereof (e.g. temperature) etc. Immersion usually means the extent to which spectators are captivated by virtual reality (Dalgarno and Lee, 2010). The more senses are stimulated by the virtual reality the more intense this stimulation is. Defining parameter of immersive visualisation is evoking the feeling of being inside the visualisation (presence, subjective presence, telepresence). The ideal means of spatial visualisation for presenting immersive models are concave, viewer-surrounding visualizations. 


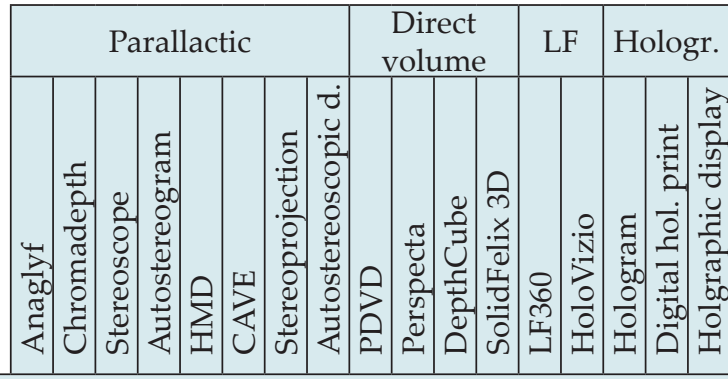

Complexicity

\begin{tabular}{|c|c|c|c|c|c|c|c|c|c|c|c|c|c|c|c|c|c|c|}
\hline \multicolumn{19}{|c|}{ Complexicity } \\
\hline Line graphics & + & + & + & + & + & + & + & + & + & + & + & + & + & & & & & + \\
\hline Graphics & $\mathrm{o}$ & $\underline{\mathrm{o}}$ & + & $\mathrm{o}$ & + & + & + & + & - & + & + & + & + & + & & + & & + \\
\hline Photographics & - & - & + & - & 0 & $\mathrm{o}$ & + & + & - & - & - & - & + & & & & & + \\
\hline \multicolumn{19}{|c|}{ Abstraction } \\
\hline Symbolic & + & + & + & + & + & + & + & + & + & + & + & + & + & + & + & + & & + \\
\hline Schematic & + & $\mathrm{O}$ & + & - & + & + & + & + & - & + & + & + & + & + & $t$ & & & + \\
\hline Realistic & $\mathrm{o}$ & - & + & - & $\mathrm{o}$ & $\mathrm{o}$ & + & + & - & + & - & - & + & & & & & $\mathrm{o}$ \\
\hline \multicolumn{19}{|c|}{ Dynamics } \\
\hline Static & + & + & + & + & + & + & + & + & + & + & + & + & + & + & & & & \\
\hline Animation & + & \pm & - & - & + & + & + & + & $\mathrm{o}$ & + & + & \pm & \pm & \pm & & & & $\mathrm{o}$ \\
\hline Dymanic & 0 & $\underline{\mathrm{o}}$ & - & - & + & + & + & + & - & + & + & - & \pm & + & $t$ & 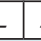 & - & - \\
\hline \multicolumn{19}{|c|}{ Color } \\
\hline Monochromatic & + & + & + & + & + & + & + & + & + & + & + & + & + & + & & + & & + \\
\hline Limited color & + & \pm & + & - & + & + & + & + & - & + & + & \pm & \pm & \pm & & + & & + \\
\hline Full color & - & - & + & - & + & + & + & + & - & + & + & t & + & + & -1 & 0 & & + \\
\hline \multicolumn{19}{|c|}{ Immersion } \\
\hline Immersive & - & - & - & - & + & + & - & - & - & - & - & - & - & & & & & - \\
\hline
\end{tabular}

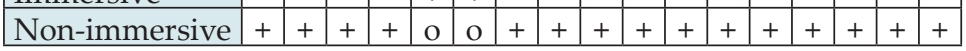

Table 2: Characteristics of visualised model depending on used technology (LF = Light Field, HMD = Head Mounted Display, CAVE

= Cave Automatic Virtual Environment, LF360 = Interactive $360^{\circ}$ LF

Display) (suitable $={ }^{\prime}+{ }^{\prime}$, partially suitable $=$ ' $0^{\prime}$, unsuitable $={ }^{\prime}-$ ')

\section{Material and Methods}

The inquiry was oriented on determining the impact of the application of spatial visualization in instruction on the results of learning as well as on spatial intelligence. The predisposition was that the level of spatial intelligence has a direct effect on the students' results or on their success at school. The assumption was also that the application of spatial visualization would lead to the improvement of students with a lower level of spatial intelligence, i.e. students that find it difficult to create an adequate mental model using planar visualization. The level of spatial intelligence was measured by a standardized test of mental rotations and the level of learning abilities by a didactical performance test. The hypothesis was that the students with a lower score on the test of mental rotations would perform better when spatial visualization is applied in the performance test than the students working with planar visualization.

The base method used in the research was the method of comparative experiment in educational settings. The experiment was organized in the form of pair selections at the given lower secondary (ISCED 2) school in 2011 and took place over two months. A group of 8th grade students (32 students, 20 boys and 12 girls) aged 14-15 were investigated. The students attended one class and during the experiment were divided into two comparable groups, wherein the instruction took place separately, but with the same teacher. The experiment was organized in three phases.

In the first (preparatory) phase the steps necessary for the creation of experimental group (E-Group) and control group (C-Group) took place. The creation of the experimental group was based on random selection from equivalent pairs of subjects to eliminate the differences and equalize the characteristics 
of individuals in the groups. The evaluation criterion was the students' score in the mental rotations test MRT (SILC, 2008). The students were also presented with a spatial imagination Santa Barbara Solids Test SBST (SILC, 2008). School results in the last 2 years based on school reports were also evaluated. There were no gender differences in the results of tests MRT $\left(A_{M}=13.1, A_{F}=12.1\right)$ and SBST, nor in the learning results.

In the preparatory phase it was proven, as expected, that there is a positive correlation between the results in mathematics and the ability of mental rotations (cor $=0.69, \mathrm{p}=0.05$ )

The experiment took place within the teaching of mathematics. The topic taught during the experiment was solid geometry. During the experiment, both the experimental and control groups underwent 10 lessons (10 x 45 minutes). The lessons took place in the same classroom (one group followed by the other). The classroom was equipped with a whiteboard and an interactive board with a digital projector. The lessons were observed by the researcher and records were made of the process as well as incident notes. The records show that the structure of the lessons was in both cases identical. The only difference was the use of spatial visualization (anaglyph) in the experiment group. In the control group the perspective or isometric visualization was used instead. Spatial visualization methods were used for 170 minutes (38 percent of the whole time) during the teaching of the experiment group. No solid models were used.

During the instruction in experiment group the teacher was active for 176 minutes (39\% of total time). Pupils worked actively 327 minutes (73\% of total time). Both sides were active 102 minutes ( $23 \%$ of total time). That means that pupils were passive only 74 minutes (16\% of total time). Administrative acts took 40 minutes (9\% of total time).
In addition whiteboard was used for 101 minutes ( $22 \%$ of total time), interactive board for 131 minutes (22\% of total time) and digital projection for 30 minutes (7\% of total time). Spatial visualisation in instruction took form of anaglyphic projection for 170 minutes (38\% of total time).

\begin{tabular}{|l|l|c|c|c|c|}
\cline { 3 - 6 } \multicolumn{2}{c|}{} & \multicolumn{2}{c|}{$\begin{array}{c}\text { Control } \\
\text { group }\end{array}$} & \multicolumn{2}{c|}{$\begin{array}{c}\text { Experimental } \\
\text { group }\end{array}$} \\
\cline { 3 - 6 } \multicolumn{2}{c|}{} & min & $\%$ & $\min$ & $\%$ \\
\hline \multirow{4}{*}{ Teaching Aids } & Textbook & 9 & $19 \%$ & 8 & $18 \%$ \\
\cline { 2 - 6 } & Workbook & 3 & $6 \%$ & 3 & $6 \%$ \\
\cline { 2 - 6 } & Exercise book & 20 & $43 \%$ & 21 & $47 \%$ \\
\hline \multirow{3}{*}{ Equipment } & Whiteboard & 9 & $19 \%$ & 10 & $22 \%$ \\
\cline { 2 - 6 } & $\begin{array}{l}\text { Interactive } \\
\text { board }\end{array}$ & 9 & $19 \%$ & 13 & $29 \%$ \\
\cline { 2 - 6 } & DVP & 3 & $6 \%$ & 3 & $7 \%$ \\
\hline $\begin{array}{l}\text { Spatial } \\
\text { visualization }\end{array}$ & $\begin{array}{l}\text { Spatial } \\
\text { visualization }\end{array}$ & 0 & $0 \%$ & 17 & $38 \%$ \\
\hline
\end{tabular}

Table 3: The lesson structure in experimental and control group

During the instruction in control group the teacher was active for 173 minutes ( $38 \%$ of total time). The pupils worked actively 327 minutes (73\% of total time). Both sides were active for 98 minutes ( $22 \%$ of total time). That means that pupils were passive only 75 minutes (17\% of total time). Administrative acts took 33 minutes ( $7 \%$ of total time).

The bigger ratio of the use of interactive board in experimental group ( $29 \%$ experimental, $19 \%$ control) is the consequence of the use of spatial visualization that was presentable only by digital projection. The interactive features of the board were not used, or they were used in the same way in both control and experimental group. 
During the experiment, the children had no problems such as headache, eye strain and other known problems when watching the anaglyphic visualization (Häkkinen, 2006).

\section{Results}

After the experiment the students of both groups, experimental and control, were given three performance tests (T1, T2, T3). Tests T1 and T3 were constructed out of common examples from everyday instruction. The test T2 was designed by the authors of the research emphasizing spatial imagination.

\begin{tabular}{|c|c|c|c|c|c|c|c|c|c|}
\cline { 2 - 11 } \multicolumn{1}{c|}{} & AT1 & RST1 & NT1 & AT2 & RST2 & NT2 & AT3 & RST3 & NT3 \\
\hline E-HIMRT & 11.8 & 69.0 & 8 & 17.3 & 63.0 & 8 & 11.4 & 69.5 & 8 \\
\hline C-HIMRT & 12.8 & 67.0 & 8 & 18.3 & 73.0 & 8 & 11.1 & 66.5 & 8 \\
\hline E-LOMRT & 6.8 & 87.0 & 8 & 11.0 & 84.0 & 8 & 12.4 & 95.0 & 8 \\
\hline C-LOMRT & 3.5 & 49.0 & 8 & 8.4 & 52.0 & 8 & 3.9 & 41.0 & 8 \\
\hline
\end{tabular}

Table 4: Final tests results $(\mathrm{A}=$ arithmetic mean, $\mathrm{RS}=$ rank sum, $\mathrm{N}=$ number of samples)

The students of both groups were divided into two sub groups. Subgroup HIMRT consisted of students that scored on MRT higher than average in the observed class. The subgroup LOMRT was made up of those scoring below average. The differences between the groups were tested on the basis of the Mann-Whitney U-Test.

In the given experiment, the students of the experimental group within subgroup LOMRT always scored better than the control group. In two cases the difference was statistically significant. On the T1 test at the level $\mathrm{p}=0.05$ and in the T3 test at $\mathrm{p}=0.01$. In the subgroup HIMRT the differences in the result of the experiment were statistically insignificant with the application of criteria at the level of $\mathrm{p}=0.05$. So it may be stated that spatial visualization has a positive influence on students with a lower level of mental rotations ability.

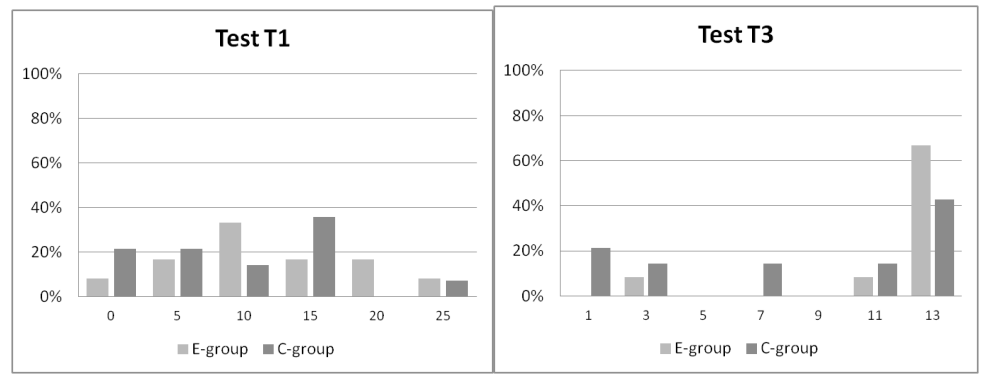

Figure 2: The relative number of results at the experimental and control groups

In the $\mathrm{T} 2$ test the scores of both groups, experimental and control, were similar $(p=0.05)$. This fact may be explained by the character of the assignments that were focused on the use of spatial intelligence not intentionally affected by the experiment. The results of both groups prove this assumption due to their equal composition.

\section{Discussion}

The empirical inquiry with its assumptions, process and main outcomes characterized in this article was focused on the research of the correlation between the form of the presentation of subject matter during instruction (planar and spatial visualization), ability of mental rotation of students, their school results, or school success. The researchers assumed that the level of spatial intelligence investigated by the test of mental rotations influences in relevant cases the results of learning and 
particularly students with lower ability of mental rotations, the presentation of subject matter by spatial visualization would lead to better understanding and acceptance.

Since a low level of mental rotation ability correlates with study results in mathematics (Prokýšek and Rambousek, 2012), test 3 shows more accurately the pupils' results in LOMRT subgroup. In HIMRT subgroup, 7 out of 12 pupils (58\%), who did the test, scored maximum points. From the viewpoint of T3 test, the pupils showed the same success rate.

Intervening variables, or their influence, in the experiment were eliminated to the maximum extent by the way they were carried out and the conditions of the experiment. The only variable which we can consider independent is the use or nonuse of spatial visualization as a didactic means. The differences in the composition of experimental and control groups were eliminated by the pair selection method. The Hawthorne effect on the examined subjects is certainly not insignificant. The influence of the researcher on the subjects was eliminated by the presence of the researcher in both experimental and control groups. Besides, the researcher was in the classroom also before the start of the experiment itself. The length of the experiment contributed to the compensation of this effect as well. During this period, the used technologies and researcher's presence became commonplace for the subjects.

The results of the experiment cannot be generalized. It should be understood as a pilot project with qualities of a case study and with results valid only in the limited group. Nevertheless it was proven that the students of LOMRT, i.e. students with a lower ability of mental rotations, that used spatial visualization during instruction scored better in tests than their counterparts using planar visualization. So the tested hypotheses were proven. It was also proven that the students of the HIMRT group i.e. subset of subjects with a higher ability of mental rotations, were not affected by the spatial visualization in terms of test scores, not even in a negative way.

\section{Conclusion}

The project, which is dealt with in this article, sought to characterize the relation between the components of spatial intelligence and the process of absorbing information presented by planar and spatial visualization when forming mental models and to verify this relation empirically. The above stated results show that using spatial visualization in learning process, which requires pupils to use spatial intelligence, is effective mainly for the pupils with less developed spatial intelligence.

The ability of mental rotations may be understood as a part of spatial intelligence that has a direct link to the effectiveness of the application of visualization into the learning process. Within the application of planar visualization it supports the formation of the mental model and the manipulation of it. Within the application of spatial visualization the ability of mental rotations is involved in the process of creating a mental model to a much lesser degree. It also shows that spatial visualization supports the creation of adequate mental models during instruction that demands certain spatial intelligence. So the students with a lower level of spatial intelligence, or with a lower mental rotation ability, profit from spatial visualization more than those with a higher level of this quality. 


\section{References}

Dalgarno, B., Lee, M. (2010) 'What are the learning affordances of 3-D virtual environments?, British Journal of Educational Technology, vol. 41, no. 1, pp. 10-32.

Esparrachiari, S. et al. (2005) 'Virtual Reality Learning Tool for Electrophysiology', Proceedings of the II Workshop TIDIA FAPESP, Sao Paolo, pp. 6-12.

Górska, R. (2005) 'Spatial Imagination an Overview of the Longitudinal Research at Cracow University of Technology', Journal for Geometry and Graphics, vol. 9, no. 2, pp. 201-208.

Häkkinen, J. et al. (2006) 'Simulator Sickness in Virtual Display Gaming : A Comparison of Stereoscopic and Non-stereoscopic Situations'. In MobileHCI 06 : Proceedings of the 8th conference on Human-computer interaction with mobile devices and services. New York : ACM, pp. 227-229.

Mikropoulos, T., Natsis, A. (2011) 'Educational virtual environments: A ten-year review of empirical research (19992009)', Computers \& Education, vol. 56, no. 3, pp. 769-780

Oh, K. E. et al. (2011) 'Which properties in 3D visualizations cause comprehension difficulties?' Proceedings of the American Society for Information Science and Technology, vol. 48, no. 1, pp. $1-4$.

Prokýšek, M. and Rambousek, V. (2012) 'Efficiency of the application of spatial visualization in instruction in relation to spatial intelligence'. In 9th International Conference on Efficiency and Responsibility in Education (ERIE 2012), pp. 481-488, Praha: ČZU Praha.

Sekuler, R. and Blake, R. (2005) Perception. (5th edition), New York: McGraw-Hill.
Schiller, P., Slocum W., Jao, B., Weiner V. (2011) ‘The integration of disparity, shading and motion parallax cues for depth perception in humans and monkeys', Brain Research, Volume 1377, Pages 67-77.

SILC (2008) Spatial Intelligence and Learning Center, [Online], Available: http://spatiallearning.org [2012-07-12].

Sorby, S. (2007) 'Developing 3D spatial skills for engineering students', Australasian Journal of Engineering Education, vol. 13, no. 1, [Online], Available: http://www.engineersmedia.com.au/ journals/aaee/pdf/AJEE_13_1_Sorby.pdf [2012-07-9].

Sternberg, R. (2002) Kognitioní psychologie : Cognitive psychology. Praha: Portál.

Tamborini, R. and Skalski, P. (2006) 'The Role of Presence in the Experience of Electronic Games'. In Playing video games : motives, responses, and consequences, pp. 225-240. 